\title{
Research Article \\ Global Epidemiology of HIV/AIDS: A Resurgence in North America and Europe
}

\author{
Romona D. Govender ${ }^{1}$, Muhammad Jawad Hashim ${ }^{1 *}, \mathbb{D}$, Moien AB Khan ${ }^{1}$, Halla Mustafa ${ }^{1}$, Gulfaraz Khan ${ }^{2,(\mathbb{D}}$ \\ ${ }^{1}$ Department of Family Medicine, College of Medicine and Health Sciences, United Arab Emirates University, Tawam Hospital Campus, \\ Al Ain 17666, UAE \\ ${ }^{2}$ Department of Medical Microbiology and Immunology, College of Medicine and Health Sciences, United Arab Emirates University, \\ Tawam Hospital Campus, Al Ain 17666, UAE
}

\section{ARTICLE INFO}

Article History

Received 24 December 2020

Accepted 21 May 2021

Keywords

HIV

AIDS

epidemiology

disease burden

prevalence

incidence

mortality

\begin{abstract}
We aimed to assess global trends in Human Immunodeficiency Virus (HIV)/Acquired Immune Deficiency Syndrome (AIDS) and evaluate progress toward eradication since the inception of the pandemic. Data were extracted from the Global Burden of Disease 2019 update and the UNAIDS Data 2019. The datasets included annual figures from 1990 to 2019 for HIV/AIDS in 204 countries and all world regions. We analyzed rates and trends for prevalence, incidence, mortality and disability adjusted life years. Analysis of age and gender distribution in different regions was used to assess demographic changes. Forecasting was used to estimate disease burden up to 2040. Although many countries have witnessed a decrease in the incidence, for Russia, Ukraine, Portugal, Brazil, Spain and the United States, the rates of new cases are rising since 2010. This trend is present even in age-standardized analysis, indicating a rise in excess of population growth. Over $0.5 \%$ of the world's population is infected. About 5000 new infections occur daily, of which 500 are children. Mortality rates are falling globally; currently at 11 deaths per 100,000 population, forecasted to decrease to 8.5 deaths by 2040. Prevalence continues to increase, with South Africa, Nigeria, Mozambique, India, Kenya and the United States having the highest burden. The total number as well as the rates of new HIV infections are rising every year in Europe, South America, North America and other regions over the last decade. Maternal-tochild transmission continues at high rates despite effective preventive regimens. There is an urgent need to develop programs to curb the rising incidence of HIV.
\end{abstract}

(C) 2021 The Authors. Published by Atlantis Press International B.V.

This is an open access article distributed under the CC BY-NC 4.0 license (http://creativecommons.org/licenses/by-nc/4.0/).

\section{INTRODUCTION}

Human Immunodeficiency Virus (HIV) and Acquired Immune Deficiency Syndrome (AIDS) continue to be a major global health tragedy despite intense efforts in international and local initiatives to address the pandemic. In 2001, the United Nations held a Special General Assembly where it was accepted that HIV/AIDS was a global public health crisis and the decision was made to intensify international action and mobilize resources to fight the pandemic. The millennium development goal six of the Millennium Declaration of 2000, initiated a concerted global effort to tackle the growing epidemic of HIV/AIDS [1]. After two decades and US\$ 109.8 billion in donor funding [2], the global community needs to re-evaluate progress across world regions.

Although antiretroviral treatment (ART) has reduced AIDSrelated deaths, access to therapy is not universal, and the prospects of curative treatments and an effective vaccine are still uncertain. It has been argued that prevention and awareness programs may prove to be more a viable approach [3]. However, these hopes were

"Corresponding author.Email: jhashim@uaeu.ac.ae; physicianthinker@gmail.com Data availability statement: All data relevant to the study are included in the article and available online at http://ghdx.healthdata.org. not materialized due to high prevalence of HIV and limited access to antiretroviral therapy among key populations [4]. HIV spread proved to be multifactorial with social factors playing an important role $[5,6]$. HIV testing had to adhere to the ethical principles protecting patient confidentiality and this together with stigma and discrimination may have hidden the disease in many societies and still continues to do so [7]. Developing countries particularly those in Africa were not geared to handle the burden that HIV/AIDS imposed on their fragile health systems [8]. This was not the only reason for the outbreak to become a pandemic. Preventive measures such as condom use, prevention of mother-to-child transmission, voluntary male medical circumcision and community awareness campaigns have been less successful than anticipated perhaps due to unaddressed systems issues [9]. Antiretroviral therapy had more People Living with HIV (PLHIV) and thus it was anticipated that the incidence and mortality will decrease. Preexposure prophylaxis, viral suppression leading to the concept of 'Undetectable = Untransmittable' $(\mathrm{U}=\mathrm{U})$, and antenatal regimens were expected to further reduce the transmission of the virus $[10,11]$. HIV infections vary by regions, even within countries $[12,13]$. These variations in HIV prevalence have important implications in the efforts to bring HIV pandemic under control. In this study, we intend to characterize the epidemiological trends of HIV/AIDS globally from 1990 to 2019 during a time of changing antiretroviral therapy. 


\section{MATERIALS AND METHODS}

Human immunodeficiency virus and acquired immune deficiency syndrome epidemiological data were analyzed from Global Burden of Disease (GBD)-2019 as well as UNAIDS Data 2019. The latter is a comprehensive and authoritative report released recently [14]. UNAIDS provides country level data from 1990 to 2019, accessible at http://aidsinfo.unaids.org/. It includes data on key populations as well as for global and regional trends. Based on officially provided national data from sentinel surveillance and routine HIV testing, the UNAIDS Data generates prevalence and mortality estimates using modelling techniques with specific parameters [15].

The GBD data for HIV/AIDS (coded as A.1.1 in GBD) were obtained from the Institute of Health Metrics Evaluation (IHME), University of Washington (downloaded from IHME database in late 2020). These estimates are part of the GBD study and include annual estimates from 1990 to 2019 for all countries and regions [16-18]. GBD provides a systematic quantification of incidence, prevalence, disability and mortality caused by HIV across different countries [19]. GBD health metrics are compiled from several primary sources including research studies, government reports and hospital registries, as well as UNAIDS Data. Estimates are generated by sophisticated modeling techniques that take into account data availability, accuracy and reliability [20]. GBD differs from UNAIDS Data as it modifies its estimates to fit within the ceiling of total deaths within each region [21].

We reviewed the incidence, prevalence, Disability Adjusted Life Years (DALYs) and mortality rates for HIV/AIDS from the most recent update by GBD. Being based on premature death and disability, DALYs provide a more accurate picture of human suffering than prevalence or mortality. The total number of cases as well as rates per 100,000 population were used to compare the burden across different countries. Forecasting was conducted using the GBD Foresight analytical tool. Age-adjusted rates were used in evaluated temporal trends to remove effects of alterations in population age structure due to migration and changes in birth and death rates.

\section{RESULTS}

\subsection{Incidence}

Human immunodeficiency virus incidence showed a resurgence over the last decade in certain regions, including North America, South America, Oceania (Western Pacific) and Europe (Figure 1A). For instance, countries such as Spain and Portugal have rising rates of newly infected cases since 2010 (Figure 2). In the US, the incidence rate rose from 15.6 new cases per 100,000 in 2010 to 21.0 cases in 2019. Total number of new infections in the US increased from 48,175 per year in 2010 to 67,000 persons contracting the virus in 2019 (in addition to pre-existing cases). This increase has been consistently rising for more than a decade. The rate of rise is alarmingly high in Russia, Portugal, Ukraine and Brazil. However, there has been a gradual reversal of this trend in Russia and Ukraine over the last 5 years. Other countries with rising incidence rates include Kazakhstan, Argentina, Mexico, Cuba, Australia and Caribbean island nations such as the Bahamas. This rising trend is present even when age-standardized rates were analyzed,
A 20
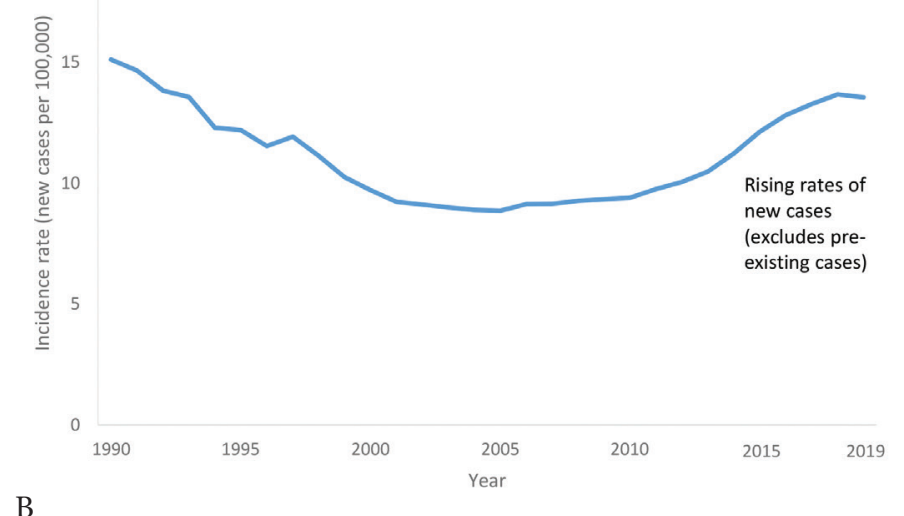

B

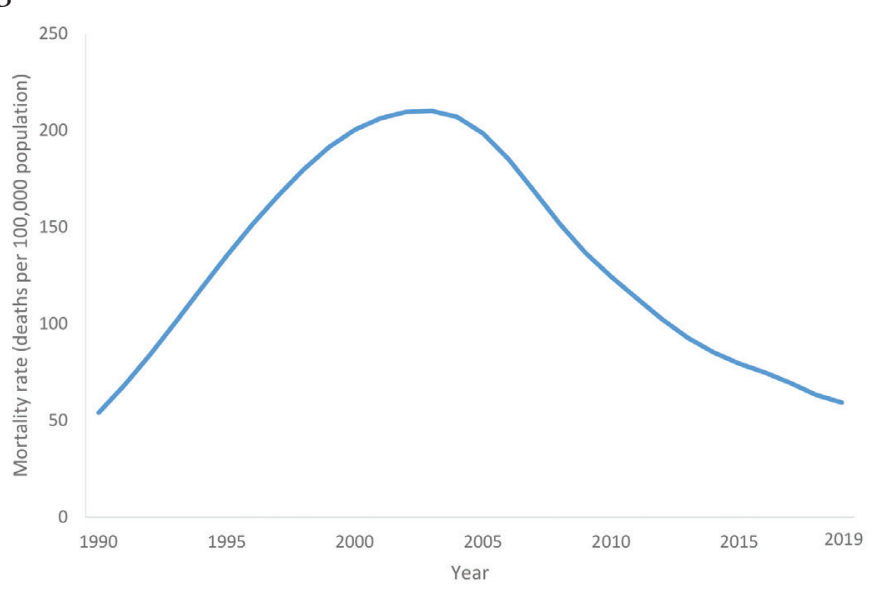

Figure 1 Epidemiological trends in HIV/AIDS. (A) Rising rates indicating a resurgence in Western Europe and the US*. (B) Falling mortality rates in sub-Saharan Africa. "Mean of incidence rates for Portugal, Spain, Italy, Germany and the US. Age-standardized rates were used to adjust for changes in population structure over time.

indicating an effect above and beyond natural population increase. The incidence rates are forecasted to continue rising for the next two decades, reaching approximately 25 new cases per 100,000 in the US (https://hiv.ihme.services/spending-impact).

In contrast, South Africa, Kenya and other African countries have witnessed a steady decrease. After a rapid rise from 1990 to 2000, the incidence of HIV/AIDS in South Africa decreased dramatically until 2005, later on the rate of decline in incidence was slower. Substantial fall in incidence rates have also been observed in China and the Indian Subcontinent (South Asia) over the last two decades. Despite the falling rates, sub-Saharan African nations still sustain the world's highest numbers of new infections by far.

\subsection{Mortality}

Mortality rates have decreased from a peak in 2005, globally as well as in sub-Saharan Africa (Figure 1B). This decline started earlier (in the mid-1990s) in countries with more developed health systems, such as Brazil and the US. The dramatic fall in deaths due to AIDS in Haiti is notable. In terms of total number of deaths, Nigeria, South Africa and Mozambique sustained the greatest burden, followed by countries such as India, China and the Russian Federation 
A 10

B

20
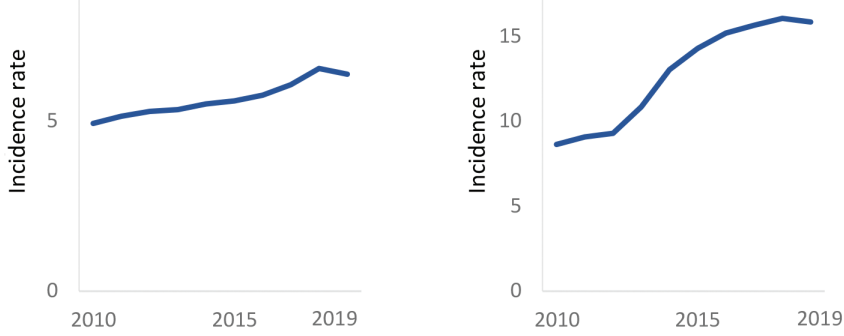

C

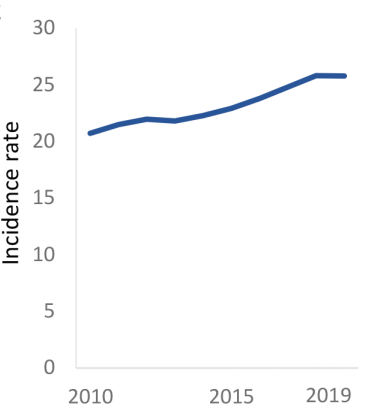

E

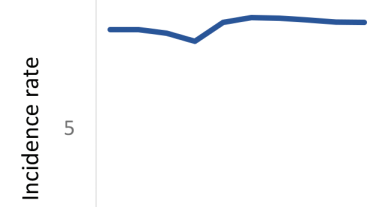
2010

$2015 \quad 2019$
$\mathrm{D}$

15
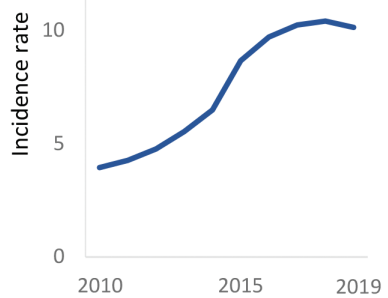

F 25

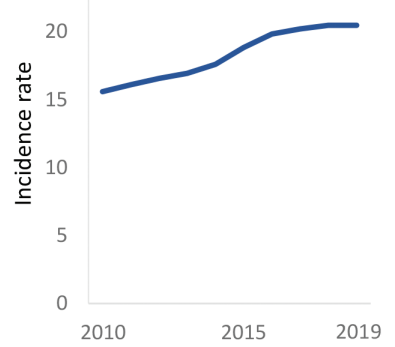

Figure 2 Rising HIV incidence rates (per 100,000 population) over the last decade in selected countries. (A) Italy. (B) Portugal. (C) Argentina. (D) Spain. (E) United Kingdom. (F) United States.

due to their large overall populations. Forecasting indicates that the current rate at 11 deaths per 100,000, will continue to decrease to 8.5 deaths by 2040 . However, an upward trend is possible in a worst case scenario.

\subsection{Prevalence}

The global burden of HIV/AIDS was 36.9 million cases in 2019, corresponding to $0.5 \%$ of the world's population, with a prevalence rate of 476 cases per 100,000. Global HIV prevalence showed a peak in 2005, decreasing for 5 years and then regaining a rising trend since 2010 (possibly due to increased survival with ART). Currently, prevalence is rising globally as well as in countries such as South Africa, Portugal, Brazil, Mexico, Peru, Spain, Germany and the United States. Both gross and age-standardized rates are rising in these countries indicating that this is well in excess of natural increase due to population growth. Portugal stands out with a rapidly rising prevalence rate, from 86 to 370 per 100,000

(from 1990 to 2019 respectively). However, this pales in comparison to South Africa's meteoric rise from 354 to 14,251 per 100,000 over the same period. Regional distribution of the burden of HIV/ AIDS is heavily concentrated in central and southern African countries such as Lesotho, Mozambique, South Africa, Zimbabwe and Namibia (Figure 3).

\subsection{Burden of Suffering (DALY)}

The true burden of this pandemic is more accurately reflected by DALYs (Table 1). Here again, several African countries from the central and southern regions show the highest burden of disability and premature deaths from AIDS related complications.

\subsection{Age Distribution}

Incidence rates of HIV show a bimodal distribution with peaks in infancy and young adults, corresponding to perinatal transmission and sexual/needle-sharing routes, respectively (Figure 4A). Ages with the highest incidence rate, after infancy, were the 20-39-year-old group (Figure 4A). According to UNAIDS Data, about 5000 new infections occur daily, of which 500 are children. Young women (15-24 years old) in sub-Saharan Africa are particularly susceptible. The ageing of HIV positive individuals due to improved survival with ART was apparent when comparing prevalence rates from 1990 and 2017 (Figure 4B). The modal age increased from 25-30 to 35-40 years old age groups, respectively. Globally, females have higher prevalence rates while males have greater mortality rates. The incidence of new cases is similar in both genders. This pattern is present in countries such as South Africa and Zimbabwe. However, in Brazil, Western Europe and the US, prevalence, incidence and mortality are all higher amongst males.

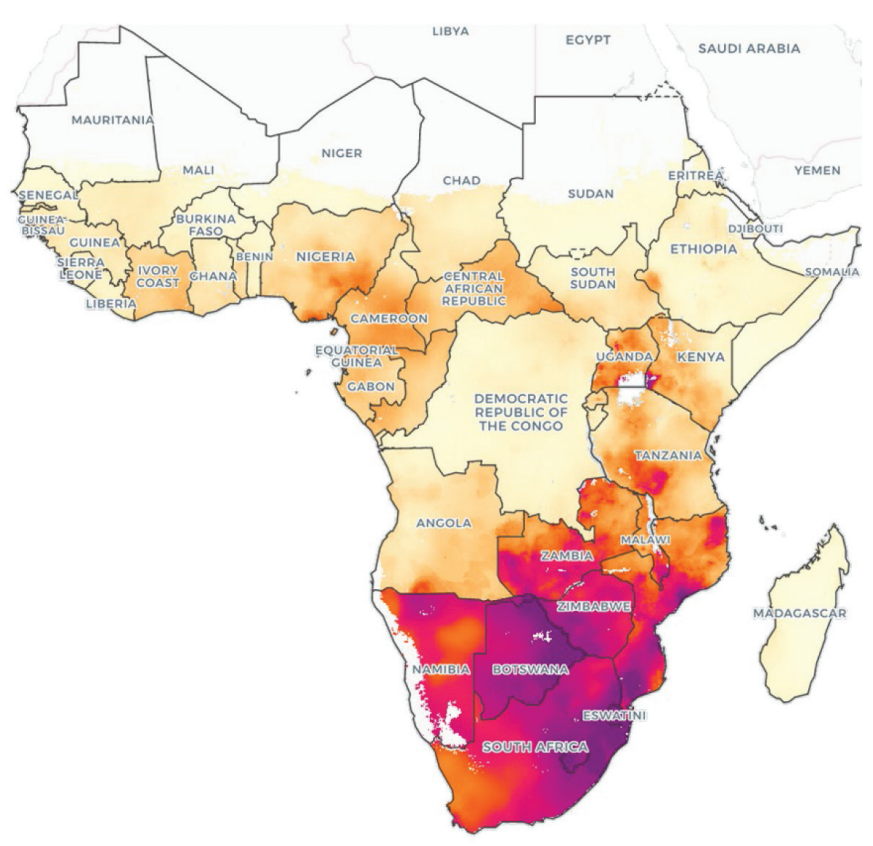

Figure 3 Geographical distribution of HIV/AIDS in Africa, ages 15-49 years, 2017. Source: IHME, Local Burden of Disease - HIV, 2017. 
Table 1 Disease burden of HIV/AIDS

\begin{tabular}{|c|c|c|c|}
\hline Region & $\begin{array}{c}\text { Prevalence rate } \\
\text { (per } 100,000 \\
\text { population) }\end{array}$ & $\begin{array}{c}\text { The burden } \\
\text { of human } \\
\text { suffering (DALY } \\
\text { per } 100,000 \\
\text { population) }\end{array}$ & $\begin{array}{c}\text { Total number } \\
\text { of cases }\end{array}$ \\
\hline Global & 476 & 616 & $36,848,000$ \\
\hline Europe & 254 & 198 & $2,155,000$ \\
\hline Germany & 94 & 27 & 80,000 \\
\hline France & 155 & 40 & 103,000 \\
\hline Italy & 160 & 54 & 96,000 \\
\hline Spain & 225 & 79 & 103,000 \\
\hline Netherlands & 123 & 22 & 21,000 \\
\hline Switzerland & 257 & 37 & 23,000 \\
\hline Russia & 776 & 730 & $1,138,000$ \\
\hline United Kingdom & 196 & 30 & 132,000 \\
\hline Asia & 100 & 157 & $4,538,000$ \\
\hline China & 39 & 98 & 551,000 \\
\hline India & 131 & 187 & $1,826,000$ \\
\hline Japan & 36 & 7 & 46,000 \\
\hline South Korea & 56 & 17 & 30,000 \\
\hline Australia & 70 & 17 & 17,000 \\
\hline Americas & 391 & 273 & $3,953,000$ \\
\hline United States & 531 & 127 & $1,743,000$ \\
\hline Canada & 253 & 49 & 92,000 \\
\hline Brazil & 411 & 373 & 891,000 \\
\hline Africa & 1990 & 2731 & $26,167,000$ \\
\hline South Africa & 14,251 & 13,821 & $7,922,000$ \\
\hline Lesotho & 17,883 & 27,335 & 374,000 \\
\hline Botswana & 15,007 & 12,406 & 351,000 \\
\hline Namibia & 8546 & 8472 & 205,000 \\
\hline Zimbabwe & 8175 & 7824 & $1,227,000$ \\
\hline Mozambique & 7977 & 13,894 & $2,355,000$ \\
\hline Zambia & 6711 & 7467 & $1,224,000$ \\
\hline Kenya & 3329 & 5448 & $1,672,000$ \\
\hline Uganda & 3323 & 3114 & $1,367,000$ \\
\hline Tanzania & 2650 & 2715 & $1,503,000$ \\
\hline
\end{tabular}

Notes: Selected countries shown in this table (all countries were included in the analysis). Data source: Global Burden of Disease, 2019.

\section{DISCUSSION}

The key finding from this study is the rising incidence of HIV in certain countries in Europe, North America and South America. This alarming finding indicates a resurgence of the epidemic over the last decade.

We found global trends that indicate considerable progress in curbing the HIV/AIDS pandemic worldwide. AIDS mortality is decreasing in most regions of the world, which is a remarkable achievement. HIV incidence reached a peak in 1998 with a rapid decline until 2005 and thereafter the graph showed a gradual and steady decline over time. Even countries like South Africa, which is an epicenter of the pandemic, showed a decline in incidence rates. Much of this success may be attributed to primary and secondary prevention programs, condom availability [22], male medical circumcision [23], pre-exposure prophylaxis (PrEP), and ART particularly for HIV-positive mother-to-child transmission. These concerted initiatives are funded by local governments as well as international donors and charitable foundations [2].

However, despite the global decline in incidence rates of HIV, countries like the US and Spain show rising incidence rates since
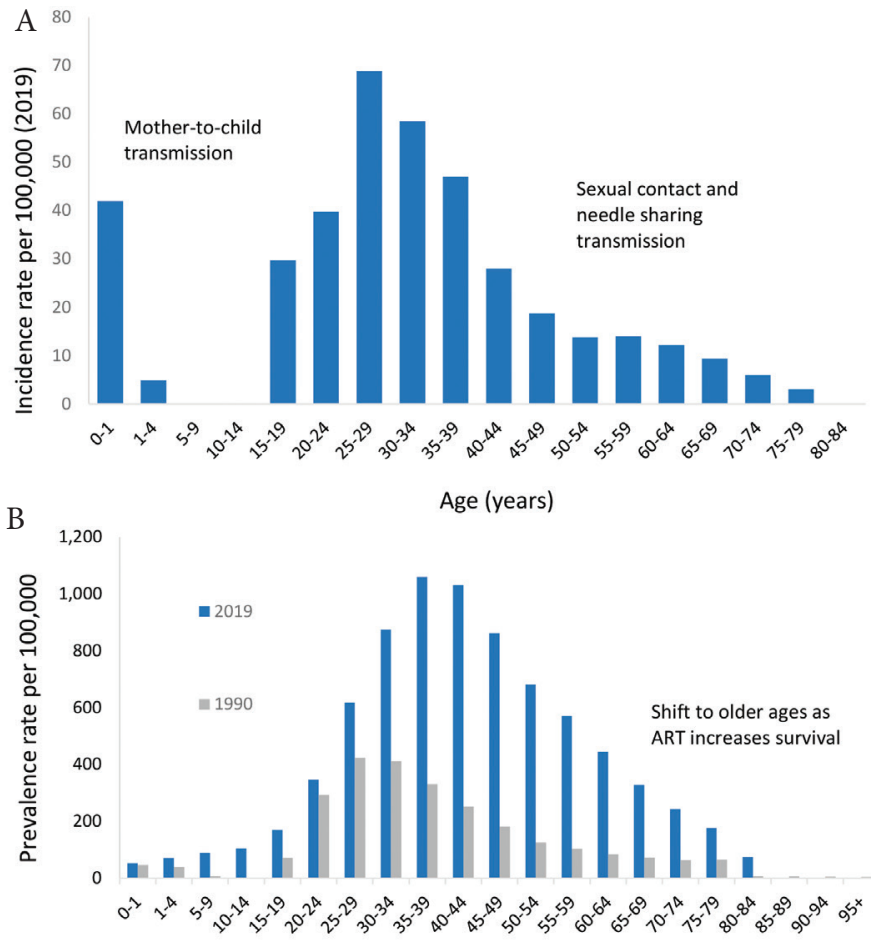

Age (years)

Figure 4 Age distribution of HIV/AIDS worldwide. (A) Incidence.

(B) Prevalence.

2010. Russia, Ukraine, Brazil, Argentina and Portugal have witnessed even higher rates. Although, the underlying reasons for this trend are not clear and need further public health research, a study by Murray et al. postulates that a slowing down of the impact of public health HIV intervention programs may explain the increasing trend notably among Men having Sex with Men (MSM) [19]. A study conducted in Portugal investigating the drivers for the increased HIV transmission rates, identified MSM and transmission of drug resistant strains of HIV as important contributors [24]. In 2016, Portugal had one of the highest diagnosis rates of HIV in Europe [17]. Other studies in Europe, Brazil and the US indicate that young MSMs are disproportionately represented in new HIV transmissions [25]. In the United States, new HIV infections have been attributed mostly to key populations such as MSM, followed by heterosexual contact, and to a lesser extent to injection-drug use $[26,27]$. In Spain, among newly diagnosed persons, the majority were aged 25-34-year-old males [28]. Indeed, no region or country in the world has reached their 2020 target [15]. The hopes of ending the AIDS epidemic in the near future are cast into doubt with this resurgence.

Successful treatment regimens of ART are shifting HIV into a chronic disease. An increasing number of people receiving ART have near normal life-expectancy, resulting in more PLHIV experiencing other chronic diseases. A major public health implication is that HIV-related healthcare needs will increase, placing a rising burden on health systems. Yet, an estimated 17.2 million individuals with HIV are not receiving ART [29]. Of those receiving ART, viral suppression is achieved in only $44 \%$.

Despite these global efforts to scale up prevention and treatment, the picture in sub-Saharan Africa remains that of an uncontrolled 
epidemic. Sub-Saharan Africa is home to only $2 \%$ of the global population, yet disproportionately accounts for one third of the global burden of HIV infection [30]. We found that HIV incidence has declined, particularly sharply in several countries in subSaharan Africa (South Africa, Kenya, Angola, Botswana, Namibia, Swaziland, Zambia and Rwanda). This improvement is most likely due to standardized treatment protocols using decentralized health service delivery, preventing mother-to-child-transmission and reducing new HIV infections through prevention. Maternal knowledge of HIV transmission prevention during pregnancy appears to be improving [31]. However, despite effective preventive regimens, we found evidence of substantial perinatal transmission. An estimated 4 million children have been infected worldwide [32]. Even with the decreasing incidence and mortality since 2005, the burden of the global HIV epidemic continues to be concentrated in subSaharan Africa.

Global Burden of Disease relies on modelling and estimation based on primary data from a multitude sources. As different primary sources have different methodologies, case definitions and case finding intensities, estimates can become less reliable. In particular, comparison across regions can be problematic due to variations in resource availability and research capacity. Also, as AIDS is a politically charged issue and remains stigmatized, there is likely to be considerable underreporting [33]. Despite these limitations, the GBD dataset is the most comprehensive and up-to-date resource on disease epidemiology. The modelling techniques used in GBD take into consideration some of these issues that affect reliability of estimates.

\section{CONCLUSION}

Our study found a concerning rise in incidence of HIV in Europe, the US and South America. This is an alarming yet underreported trend. Despite intense research and substantial public health expenditure, the total number of newly infected cases is rising every year in these countries. The design and implementation of national HIV programs will determine the course of the epidemic. Prevention interventions should involve and engage key populations. SubSaharan Africa continues sustain unbearably high burden and accounts for untold human suffering. This analysis provides insights into the current and future trends to achieve eradication of the HIV epidemic. Achieving such a goal will not only require funding for universal ART access, but also more effective sociocultural strategies for HIV prevention.

\section{CONFLICTS OF INTEREST}

The authors declare they have no conflicts of interest.

\section{AUTHORS' CONTRIBUTION}

$\mathrm{MJH}$ conceived and designed the study. $\mathrm{HM}$ and $\mathrm{MJH}$ performed the data collection and analysed the data. RDG, HM, MABK and $\mathrm{MJH}$ wrote the paper. RDG, MJH, MABK, HM and GK revised the paper.

\section{REFERENCES}

[1] Mabaso MLH, Zama TP, Mlangeni L, Mbiza S, MkhizeKwitshana ZL. Association between the Human Development Index and millennium development goals 6 indicators in subSaharan Africa from 2000 to 2014: implications for the New Sustainable Development Goals. J Epidemiol Glob Health 2018; $8 ; 77-81$.

[2] Schneider MT, Birger M, Haakenstad A, Singh L, Hamavid H, Chapin A, et al. Tracking development assistance for HIV/ AIDS: the international response to a global epidemic. AIDS 2016;30;1475-9.

[3] Show KL, Shewade HD, Kyaw KWY, Wai KT, Hone S, Oo HN. HIV testing among general population with sexually transmitted infection: findings from Myanmar demographic and health survey (2015-16). J Epidemiol Glob Health 2020;10; $82-5$.

[4] Jonas A, Patel SV, Katuta F, Maher AD, Banda KM, Gerndt K, et al. HIV prevalence, risk factors for infection, and uptake of prevention, testing, and treatment among female sex workers in Namibia. J Epidemiol Glob Health 2020;10;351-8.

[5] Mashragi F, Bernstein RS, Al-Mazroa M, Al-Tawfiq JA, Filemban S, Assiri A, et al. HIV transmission at a Saudi Arabia hemodialysis unit. Clin Infect Dis 2014;59;897-902.

[6] Memish ZA, Filemban SM, Bamgboyel A, Al Hakeem RF, Elrashied SM, Al-Tawfiq JA. Knowledge and attitudes of doctors toward people living with HIV/AIDS in Saudi Arabia. J Acquir Immune Defic Syndr 2015;69;61-7.

[7] Gökengin D, Doroudi F, Tohme J, Collins B, Madani N. HIV/ AIDS: trends in the Middle East and North Africa region. Int J Infect Dis 2016;44;66-73.

[8] Case A, Paxson C. The impact of the AIDS pandemic on health services in Africa: evidence from demographic and health surveys. Demography 2011;48;675-97.

[9] Kumar A, Singh B, Kusuma YS. Counselling services in prevention of mother-to-child transmission (PMTCT) in Delhi, India: an assessment through a modified version of UNICEF-PPTCT tool. J Epidemiol Glob Health 2015;5;3-13.

[10] Maemun S, Mariana N, Rusli A, Mahkota R, Purnama TB. Early initiation of ARV therapy among TB-HIV patients in Indonesia prolongs survival rates!. J Epidemiol Glob Health 2020;10; $164-7$.

[11] Nguyen VK, Greenwald ZR, Trottier H, Cadieux M, Goyette A, Beauchemin $M$, et al. Incidence of sexually transmitted infections before and after preexposure prophylaxis for HIV. AIDS 2018;32;523-30.

[12] Elgalib A, Shah S, Al-Wahaibi A, Al-Habsi Z, Al-Fouri M, Lau R, et al. The epidemiology of HIV in Oman, 1984-2018: a nationwide study from the Middle East. J Epidemiol Glob Health 2020;10;222-9.

[13] Memish ZA, Al-Tawfiq JA, Filemban SM, Qutb S, Fodail A, Ali B, et al. Antiretroviral therapy, CD4, viral load, and disease stage in HIV patients in Saudi Arabia: a 2001-2013 cross-sectional study. J Infect Dev Ctries 2015;9;765-9.

[14] UNAIDS data 2019. Joint United Nations Programme on HIV/ AIDS 2019. Available from: https://www.unaids.org/en/resources/ documents/2019/2019-UNAIDS-data (accessed September 27, 2020). 
[15] Mahy M, Marsh K, Sabin K, Wanyeki I, Daher J, Ghys PD. HIV estimates through 2018: data for decision-making. AIDS 2019;33;S203-S11.

[16] Khan G, Hashim MJ. Burden of virus-associated liver cancer in the Arab world, 1990-2010. Asian Pac J Cancer Prev 2015;16;265-70.

[17] Khan G, Hashim MJ. Global burden of deaths from Epstein-Barr virus attributable malignancies 1990-2010. Infect Agents Cancer $2014 ; 9 ; 38$.

[18] Hashim MJ, Al-Shamsi FA, Al-Marzooqi NA, Al-Qasemi SS, Mokdad AH, Khan G. Burden of breast cancer in the Arab World: findings from Global Burden of Disease, 2016. J Epidemiol Glob Health 2018;8;54-8.

[19] Murray CJL, Ortblad KF, Guinovart C, Lim SS, Wolock TM, Roberts DA, et al. Global, regional, and national incidence and mortality for HIV, tuberculosis, and malaria during 1990-2013: a systematic analysis for the Global Burden of Disease Study 2013. Lancet 2014;384;1005-70.

[20] GBD 2015 HIV Collaborators. Estimates of global, regional, and national incidence, prevalence, and mortality of HIV, 19802015: the Global Burden of Disease Study 2015. Lancet HIV 2016;3;e361-e87.

[21] GBD 2017 HIV collaborators. Global, regional, and national incidence, prevalence, and mortality of HIV, 1980-2017, and forecasts to 2030, for 195 countries and territories: a systematic analysis for the Global Burden of Diseases, Injuries, and Risk Factors Study 2017. Lancet HIV 2019;6;e831-e59.

[22] Rehle TM, Hallett TB, Shisana O, Pillay-van Wyk V, Zuma K, Carrara $\mathrm{H}$, et al. A decline in new HIV infections in South Africa: estimating HIV incidence from three national HIV surveys in 2002, 2005 and 2008. PLoS One 2010;5;e11094.

[23] Kong X, Kigozi G, Ssekasanvu J, Nalugoda F, Nakigozi G, Ndyanabo A, et al. Association of medical male circumcision and antiretroviral therapy scale-up with community HIV incidence in Rakai, Uganda. JAMA 2016;316;182-90.

[24] Pineda-Peña AC, Pingarilho M, Li G, Vrancken B, Libin P, Gomes P, et al. Drivers of HIV-1 transmission: the Portuguese case. PLoS One 2019;14;e0218226.

[25] Beyrer C, Sullivan P, Sanchez J, Baral SD, Collins C, Wirtz AL, et al. The increase in global HIV epidemics in MSM. AIDS 2013;27;2665-78

[26] Patel P, Borkowf CB, Brooks JT, Lasry A, Lansky A, Mermin J. Estimating per-act HIV transmission risk: a systematic review. AIDS 2014;28;1509-19.

[27] Dosekun O, Fox J. An overview of the relative risks of different sexual behaviours on HIV transmission. Curr Opin HIV AIDS 2010;5;291-7.

[28] Ayerdi Aguirrebengoa O, Vera Garcia M, Rueda Sanchez M, D'Elia G, Chavero Méndez B, Alvargonzalez Arrancudiaga M, et al. Risk factors associated with sexually transmitted infections and HIV among adolescents in a reference clinic in Madrid. PloS One 2020;15;e0228998.

[29] Eisinger RW, Fauci AS. Ending the HIV/AIDS pandemic. Emerg Infect Dis 2018;24;413-16.

[30] De Cock KM, Jaffe HW, Curran JW. The evolving epidemiology of HIV/AIDS. AIDS 2012;26;1205-13.

[31] Sahlu I, Howe CJ, Clark MA, Marshall BDL. HIV status, knowledge of mother-to-child transmission of HIV and antenatal care use among Ethiopian women. J Epidemiol Glob Health 2014;4; $177-84$.

[32] Flynn PM, Abrams EJ. Growing up with perinatal HIV. AIDS 2019;33;597-603.

[33] Memish ZA, Filemban SM, Kasule SN, Al-Tawfiq JA. Knowledge and attitudes about HIV/AIDS in illegal residents in the Kingdom of Saudi Arabia. J Glob Infect Dis 2015;7;103-7. 